\title{
Assistive Tools towards Personal Learning Environment in Higher Education
}

\author{
Nooralisa Mohd Tuah, Dg Senandong Ajor, and Nuraini Jamil
}

\begin{abstract}
This study explores the tools and materials used in personal learning environment (PLE) by investigating the impact of embedding a mashup technology into learning environment. With Web 2.0 technologies, mashing up several materials into learning repository helps learners to form their own scope of learning. A PLE mashup model is suggested in determining suitable tools and materials. Based on the current trends in Web 2.0, another aspect of PLE that could be further investigated is the adoption of social media application for formal higher education level. A study on student perception shows a positive acceptance towards PLE in their learning activities. In order to serve as learning tool, how the technology could be implemented, and its limitation towards efficiency was highlighted.
\end{abstract} 2.0.

Index Term-Personal learning environment, mashup, web

\section{INTRODUCTION}

The rapid growth of internet technologies has changed the way formal learning facilitates the educational environment. Traditionally, classroom is the only medium of communication and information sharing. Current e-learning environment such as learning management system (LMS), Blackboard, Moodle are amongst the platforms used and are widely accepted in the educational institutions. Generally, with the adoption of Web 2.0 in e-learning's model, elearning has dynamically delivered classroom content (notes, tutorial, etc.) to its participants (teachers and students). Soumplis, A. et al. [1] argued that the current e-learning platforms had failed its purpose in adapting the Web 2.0 functions. Some of the Web 2.0 functions require active participation from the user where user's role is not as a passive consumer of content but as an active creator of the content.

Ros et al. [2] defined learning management system as a collection of services where the system will let users to select any available services from multiple providers and mix it with other learning activities in one platform. Thus, the users should at least be able to construct their own learning environment. Antti Syvänen et al. [3] advocated that social media applications as another component that should be added and applied in learning environment. The implementation of social media applications in learning environment will allow users to create, maintain and

Manuscript received June 10, 2014; revised August 5, 2014. This work was supported in part by the Faculty of Computer and Informatics, University Malaysia Sabah.

Nooralisa Mohd Tuah, Dg Senandong Ajor, and Nuraini Jamil are with the Faculty of Computer and Informatics, University Malaysia Sabah, Labuan F.T, Malaysia (e-mail: aelise@ums.edu.my, dyg_ajor@ums.edu.my, ainjamil@ums.edu.my). rearrange their own content. These new age tools introduce a new way of learning in Personal Learning Environment (PLE). PLE enables the existing e-learning tools to be more open and collaborative. Attwell [4] in his prediction on the future of eLearning has suggested the use of web 2.0 in mashing up learning resources, learning services and communities of their choices together. Therefore, mashup technology is an interesting technology to be explored and implemented in PLE.

This paper presents our study on the evolving scenarios of personal learning environment, particularly looking at how efficient it can be and how mashup should be implemented as well as how social media influences the success of PLE. In Section II, the introduction of Mashup technology is presented before looking in depth of its implementation towards PLE in Section III. In Section IV, we investigate how social media affected the PLE. Based on that discussion, a PLE model is suggested in Section V. Students' perceptions of PLE in their learning activities are studied in Section VI and the summarization of investigation is presented in Section VII.

\section{MASHUP}

Web application environment has moved forward in line with the evolvement of technology in application development. Traditional approach is no longer can support massive data information on the web. The extension of web 2.0 and semantic web architecture has created a different approach in utilizing the data on the web [5], [6]. Therefore, data synchronization becomes more important to cater the increasing demand for faster and easier access to the needed information. Mashup refers to web page application that seamlessly combines several data resources and presentations from different destinations or reusable resources for web services [5], [7], [8]. The integration of content and functionality through open Web APIs [5], [9], [10] promotes a new style of communication that enables users to create their own applications. Mashup development requires APIs or content providers such as open data (example: RSS, ATOM), open services (example: REST, SOAP, XML) and/or mashup tools. Based on that combination, few mashup approaches have been identified and discussed to facilitate mashup development. This includes widget-based [9], spreadsheet-like [11], wired-based [5], programming by example and demonstration [12], [13] and block-based development [14]. These approaches play an important role as a user interface component at the presentation level. Based on composition mashup architecture model in [7], [9], [10], we illustrated the mashup environment as in Fig. 1, for application development and to make it easier to be 
comprehended for our suggested model in Section V. At presentation level, mashup use widgets as interfaces [9] and these widgets are widgetized by Inter Widget Communication (IWC) framework. At data level, mashup utilize data query languages $(Y)$ to extract information and any suitable web programmable framework $(X)$ to linkage the data sources. All widgets and data sources will be synchronized by event handler. On the other hand, there are a number of mashup tools ready to be used as the editor, currently available in the market such as Yahoo! Pipes, Google Mashup Editor and Intel Mash Maker. These tools will speed up the development process and at the same time help users mashing their own applications. In general, a mashup application is an application that combines contents from several resources into an integrated web application which is supported by the technology to communicate between tools and to integrate them for a meaningful application.

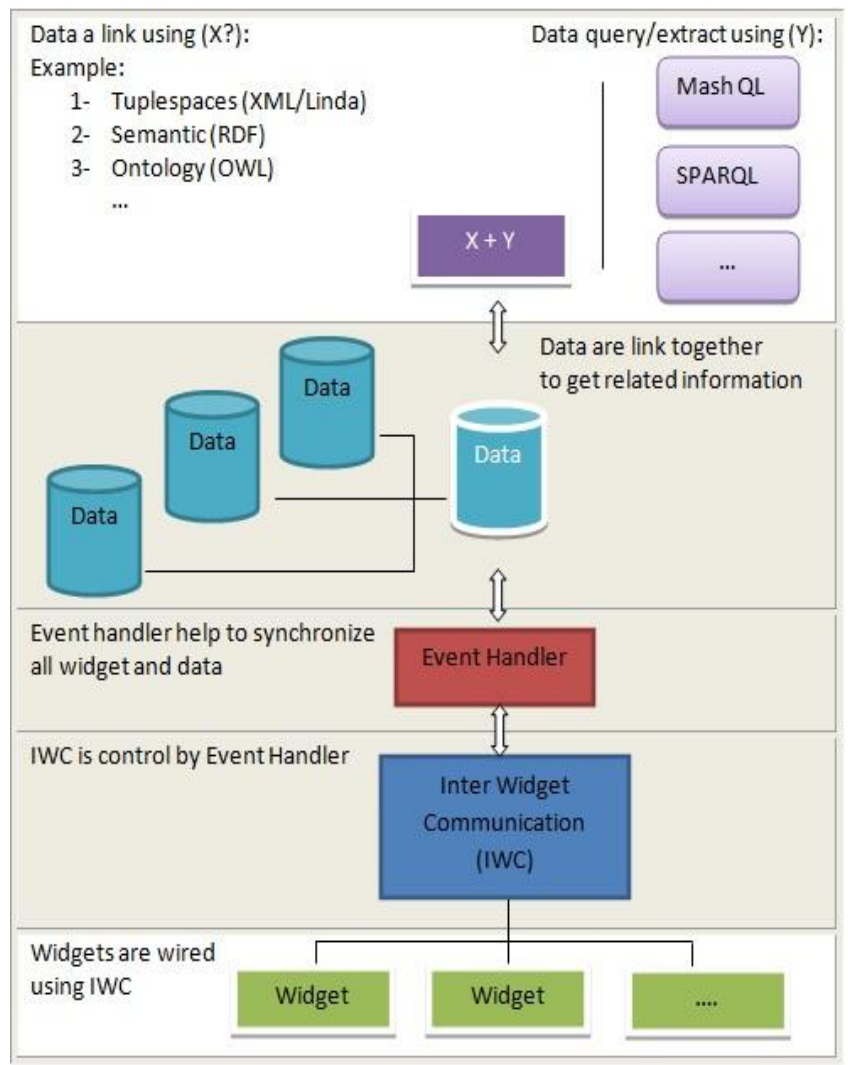

Fig. 1. Mashup environment.

\section{MAShuP In PeRsonal LEARNING ENVIRONMENT}

Mashup technology in Web 2.0 is still vague in practice. The technology behind it and the application based on it are built up from different sources. Study on mashup technology and its architecture on how to improve the services and widget interoperability have been done widely. However, there is still a question on how to implement it effectively. Apparently, based on its nature, mashup is suitable for a simple and small application [5]-[7]. Therefore, Daniel [8] suggested that the application towards a specific domain will help user to understand the mashup platform as well as create a better way of engaging with the user. Regardless of mashup growing popularity, education is one of the interesting domains to be explored.
Mashup application is suggested for personal learning environment (PLE) for higher education where an individual course offers its own information sources and learning activities. This mashup application will enable educators to create attractive and interactive learning activities, and also allows students to personalize their learning environment. Mashup with web 2.0 tools provides particular opportunities for personalized learning to improve the learning experience. With the available vast information for educations continues to expand, a mashup could be the solution towards simplifying the development of high-quality course-specific content. With the progression of web 2.0 technologies, the main reason of having PLE in students' courses is to customize the PLE to the particular students' learning styles [1], [4], [15], [16]. With real time information, user (student and educator) can monitor their class information and participate in their class activities simultaneously. This creates dynamic learning communities within courses.

Another concept in PLE is to accommodate individual learning repository and information towards personal achievement and target for their study. This concept will create a dynamic learning progression per student, however it is still lacking in implementation. It is probably because to get information individually, each course needs to be fully implemented so that all students' courses can be formulated. To do this, a wider scope of implementation is required. Functioning neither as an individual nor as a course itself, PLE should facilitate both learner and educator. In this paper, we focus more towards class-specific content. PLE is not new in the education environment. However, its effectiveness may vary, and it is an open issue that continues to evolve from time to time. One that could be explored is the use of PLE with social media for formal education.

\section{PLE WITH SOCIAL MEDIA}

Social media applications such as blogs, Twitter, Facebook, etc., have great influence on education. Many institutions used social media as one of their teaching mediums for activities such as sharing information, announcement and news, exchanging ideas and so on. This is because social media application provides an environment with interactive interfaces, great accessibility and user friendliness. Therefore, it becomes a driving motivation towards an effective learning. However, in higher education, implementing social media in learning is not professional and formal [16], [17]. Learning Management System (LMS) was introduced way before social media is implemented and it has lots of function that could replace traditional class management. LMS is a platform for e-learning that enables effective content assembly and delivery.

LMS has evolved from time to time with the advancement of technology. However, in some cases [18], it has failed its function of delivering learning purposes due to some of its unusable functions. There are too many functions provided in one platform without focusing on the significant one. Gillet, D. et al. [17] suggested that an e-learning should not be too complex to operate and should only provide functions related to the course content such as news feed, discussion forum, notes sharing, task and class activities. These functions are exactly what those social media applications tried to adopt in 
our learning environment. With little modification and user's personal involvement, the PLE is now becoming feasible and highly recommended for e-learning classes.

Furthermore, it is noticeable that the social media application's architecture offers a light platform for a faster transaction. This is why user especially student prefer to use it for formal interaction in learning. In addition, social media application features could also be available through mobile devices, and this facilitates active involvement by the users. Thus, implementing social media applications in PLE is highly recommended. This should be modeled to further investigate the concepts in depth.

\section{PLE MODEL}

The idea of PLE is to create a personal repository for all content that have been created individually in order to manage the learning activities within one course or class [2]. We can see that the PLE application concept is more or less like LMS but in a smaller scope and more focus towards specific domain (course or class). PLE using mashup architecture is a concept of distributed application and it is connected by using content provider and services. Based on other suggested mashup architectures [1], [2], [17], [19], we come out with a simple model as in Fig. 2, to describe how PLE can be implemented. In this model, we introduced the involvement of social media application formally in learning environment in order to replace the existing forum activity or personal messaging systems.

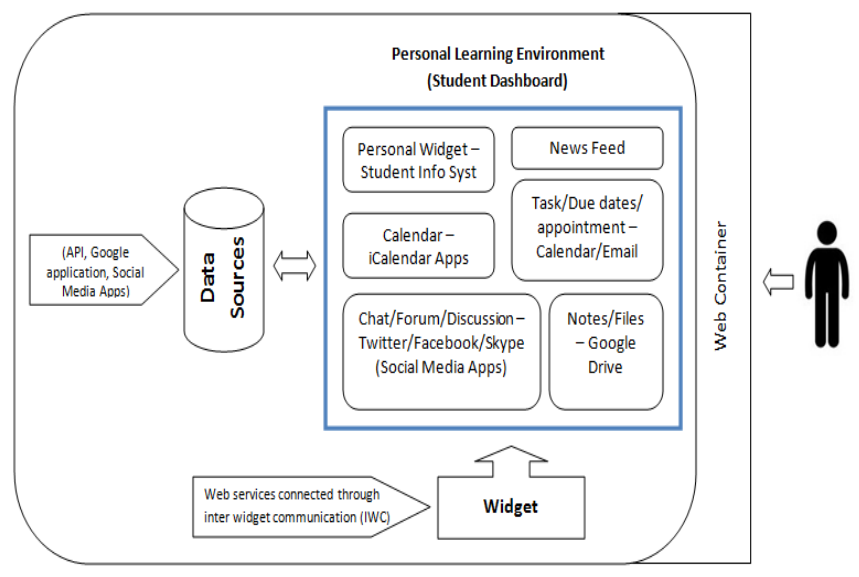

Fig. 2. Model personal learning environment.

As shown in Fig. 2, the model consists of several components. The student information system is the main sources for each student. Other components (in blue box) involve functions such news feed (for announcements), calendar, email, and files sharing, which are from open and collaborative application. This open and collaborative application could be an application that is already in the market provided by Google, Microsoft, Yahoo, etc. These technologies are offered to users in a way they can utilize and maximize it according to their preferences. Another involvement in this model is from social media application especially for news feed and discussion session. Direct communication among users through social media application may greatly improve the efficiency of knowledge and information sharing [17], [19]. It brings together personal and social learning into practices, hence enabling formal and informal forms of learning to be part of higher education environment.

This model is planned to be implemented into Mashup architecture as discussed in section II. All suggested components in this model are supported by widget and data sources. A widget is an application that has its own graphical user interface and is presented as web services where users are able to drag and drop onto the mashup environment. It will be widgetized or wired using IWC framework [5], [7], [9]. IWC will be supported by event handler where it helps to synchronize related widget and data. As data suppliers, data sources will control the information transition among all applications. Above all, the application can be accessed by users through a web container.

\section{StUdent PERCEPTION TOWARdS PLE}

Our previous research [18] on students' satisfaction in using LMS showed that LMS could not deliver the classroom's environment virtually. Students need more interactive online platform to encourage them. Thus, PLE could be introduced for this purpose. Most previous research [1], [2], [15]-[17] showed a positive response towards PLE's implementation.

Research conducted by Ros S. et al. [2] in predicting the future learning for PLE, had shown a positive acceptance by their students, particularly in terms of system's utility (function) and usability. The students believed that using the virtual course with external gadgets has really helped improving their learning motivation. It lets them combine both learning and leisure. Llorente Cejudo [15] also obtained a very positive result from the expert (university teacher) evaluation on the feasibility of technical operation, tools performing PLE and learning repository.

Soumplis A. et al. [1] in his research on exploring the potential use of PLE in education had further emphasized on the usability experience rather than the technology behind it This is to attract more users to enhance their experiences. Pozgaj and Vuksic [16] had conducted an investigation on the implication process of e-learning using PLE. Besides the positive attitude towards PLE, they also found that students were more interested in using it for leisure than for real learning. On the other hand, Gillet et al. [17] suggested a new approach on how to integrate personal and social activities for learning purposes. Based on their research, students were happy to get all necessary materials in one platform. Based on the previous researches, it can be concluded that PLE is actually accepted by students either for formal or informal purposes. However, the challenge for PLE is to formulate it to achieve its purpose as a tool for a better learning.

\section{CONCLUSION AND FUTURE WORK}

Lately, PLE has become one of the reference topics in learning strategy at higher education level. However, most of the prior researches were about perception and acceptance by the students and educators. There were also researches that provided comparison between PLE and LMS. PLE is considered as a new era of learning supported by web 2.0/3.0 technology. However, there are still some areas to be explored in the implementation of PLE in learning, 
particularly in terms of material or sources that have a significant effect towards the student. A design model consisting of those materials needs to be formalized and clearly organized to align with user's interest and proficiency. Besides the concept of learning, technological aspect has also played an important role. In this research, PLE is suggested to be implemented by using mashup technology. Based on the suggested model, social media application is considered to be one of the factors towards a successful implementation considering the current trends in Web 2.0 structure and students' activities. There are two main challenges that need to be addressed. One is about the PLE concept itself in terms of pedagogical point of view and the other one is about mashup technology in terms of the integration technology, usability and security in data sharing. In our future development, we would develop a mashup application for PLE in both mobile and desktop based on the suggested model in this study. Subsequently, it will then be implemented in school's learning environment.

\section{ACKNOWLEDGMENT}

We thank the Faculty of Computing and Informatics, and University Malaysia Sabah for their support in the realization of this research.

\section{REFERENCES}

[1] A. Soumplis, E. Chatzidaki, E. Koulocheri, and M. Xenos, "Implementing an open personal learning environment," in Proc. 15th Panhellenic Conference on Informatics (PCI), 2011, pp. 345-349.

[2] S. Ros, R. Hernandez, A. Robles-Gomez, A. C. Caminero, L. Tobarra, and E. S. Ruiz, "Open service-oriented platforms for personal learning environments," in Proc. IEEE Internet Computing, 2013, vol. 17, no. 4, pp. 26-31.

[3] A. Syvänen, J. Muukkonen, and M. Sihvonen. "Are the open issues of social software-based personal learning environment practices being addressed?" in Proc. the 13th International MindTrek Conference: Everyday Life in the Ubiquitous Era (MindTrek '09), ACM, New York, NY, USA, pp. 142-148.

[4] G. Attwell, "The personal learning environments - The future of eLearning?" eLearning Papers, vol. 2, no. 1, 2007.

[5] A. Soylu, F. Wild, F. Mödritscher, P. Desmet, S. Verlinde, and P. De Causmaecker, "Mashups and widget orchestration," in Proc. the International Conference on Management of Emergent Digital EcoSystems (MEDES '11), ACM, New York, NY, USA, 2011, pp. 226-234.

[6] B. Erb, J. P. Elsholz, and F. J. Hauck, "Semantic mashup," Technical Report (VS-R08-2009), Ulm University, 2009.

[7] N. Zang, "Mashups on the web: end user programming opportunities and challenges," in Proc. First Workshop on Evaluation and Usability of Programming Languages and Tools, 2009.

[8] F. Daniel, M. Matera, and M. Weiss, "Next in mashup development: User-created apps on the web," IEEE Computer Society, IT Professional, vol. 13, no. 5, pp. 22-29, Sept.-Oct. 2011.

[9] T. Sheng, W. Gerald, and L. Christof, "A tuplespace event model for mashups," in Proc. the 23rd Australian Computer-Human Interaction Conference (OzCHI '11), ACM, New York, NY, USA, 2011, pp. 281290.
[10] J. Yu, B. Benatallah, S.-P. Regis, F. Casati, F. Daniel, and M. Matera "A framework for rapid integration of presentation components," in Proc. the 16th International Conference on World Wide Web, ACM New York, NY, USA, 2007, pp. 923-932.

[11] W. Kongdenfha, B. Benatallah, J. Vayssière, R. Saint-Paul, and F. Casati, "Rapid development of spreadsheet-based web mashups," in Proc. The 18th International Conference on World Wide Web, Madrid, Spain, 2009, pp. 851-860.

[12] R. Tuchinda, C. A. Knoblock, and P. Szekely, "Building mashups by demonstration," ACM Trans. Web, vol. 5, no. 3, pp. 45, July 2011.

[13] R. Tuchinda, P. Szekely, and C. A. Knoblock, "Building mashups by example," in Proc. the 13th International Conference on Intelligent User Interfaces, ACM, New York, NY, USA, 2008, pp. 139-148.

[14] R. Latih, A. M. Patel, A. M. Zin, T. Yiqi, and S. H. Muhammad, "Whip: A framework for mashup development with block-based development approach," in Proc. 2011 International Conference on Electrical Engineering and Informatics, 17-19 July 2011, pp. 1-6.

[15] M. L. Cejudo, "Assessing personal learning environments (PLEs): An expert evaluation," Journal of New Approaches in Educational Research, vol. 2, no. 1, pp. 39-44, 2013.

[16] Z. Pozgaj and V. B. Vuksic, "Personal learning environments: The implication on process of e-learning," in Proc. the 35th International Convention, 21-25 May, 2012, pp. 1135-1140.

[17] D. Gillet, E. L. C. Law, and A. Chatterjee, "Personal learning environments in a global higher engineering education web 2.0 realm," IEEE Education Engineering (EDUCON), pp. 897-906, 2010.

[18] J. Mina, T. K. V. Nicholas, M. T Nooralisa, J. Nuraini, and A. Dg Senandong, "Significant effect of TAM model on students" satisfaction use of learning management system," in Proc. the 2013 International Conference on Computer Science and Information Technology (CSIT), Yogjakarta, Indonesia, 16-18 June 2013.

[19] M. M. Vazquez and M. Llamas-Nistal, "Distributed personal learning environments towards a suitable architecture," in Proc. IEEE Global Engineering Education Conference (EDUCON), 2013, pp. 664-673.

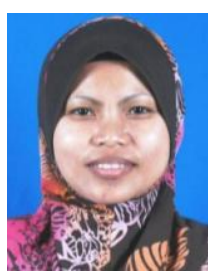

Nooralisa Mohd Tuah is a lecturer in the Faculty of Computing and Informatics at the Universiti Malaysia Sabah for e-Commerce program. Her interests include web engineering methodology for rich internet application, mashup architecture, and human computer interaction usability.

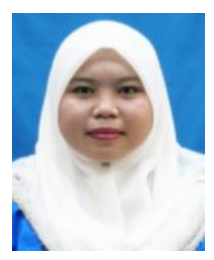

Dg Senandong Ajor received her bachelor's degree with honours in management information system from the International Islamic University Malaysia (IIUM) in 2004, and the MSc degree in knowledge discovery and data mining from the University of East Anglia (UEA), Norwich, UK in 2009. Her current research interests include rich internet application, e-learning, web mining and big data analytics.

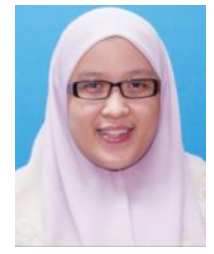

Nuraini Jamil is currently a lecturer in the Faculty of Computing and Informatics, the University Malaysia Sabah. Her research interests include image processing and classification, semantic similarity, and multimedia system. 